\title{
A decolonidade do corpo e das artes de Aleta Valente
}

\section{Muriel Emídio Pessoa Amaral}

\author{
Universidade Estadual \\ de Ponta Grossa \\ Ponta Grossa, PR, Brasil \\ murielamaral@yahoo.com.br \\ orcid.org/0000-0003-3069-6697
}

\begin{abstract}
The decoloniality of the body and the arts of Aleta Valente

Abstract | Based on the works produced by the Carioca artist and performer Aleta Valente, this article intends to discuss how her productions can be considered and analyzed according to the epistemological point of view of decoloniality, suggested by Walter Mignolo, and of contemporaneity, thought by Giorgio Agamben. In the face of these ideas and concepts, Aleta Valente makes the aridity of the suburb, hair and menstruation arguments for her art in feminist discourses of empowerment and debauchery to patriarchy and to the artistic production's system.
\end{abstract}

KEYWORDS: Arts. Decoloniality. Aleta Valente.

La decolonidad del cuerpo y las artes de Aleta Valente

Resumen I A partir de las obras realizadas por la artista e performancer carioca Aleta Valente, este artículo pretende discutir cómo sus producciones pueden ser consideradas $y$ analizadas desde el punto de vista epistemológico de la decolonidad, sugerido por Walter Mignolo, y la contemporaneidade pensada por Giorgio Agamben. Pensar desde la decolonidad es reconecer nuevas propuestas epistemológicas y políticas que van más allá del pensamiento eurocéntrico o fundamentalmente cristalizado desde la perspectiva del poder. Frente a esta idea, Aleta Valente utiliza la aridez de la periferia, el cabello y la menstruación como argumentos de su arte en los discursos feministas de empoderamiento y burla al patriarcado y los sistemas de producción artística.

PALABRAS CLAVE: Artes. Decolonidad. Aleta Valente.

Enviado em: $13 / 02 / 2021$

Aceito em: 17/08/2021

Publicado em: 30/09/2021

PALAVRAS-CHAVE: Artes.

Decolonidade. Aleta Valente. 


\section{Introdução}

Pensar a sexualidade, o corpo e as suas performatividades nas artes é desenvolver ideias que não devem ficar restritas aos posicionamentos que foram canonizados pelas práticas artísticas desenvolvidas ao longo de vários anos. Sugerir o corpo nas artes contemporâneas vai além da simetria e proporcionalidade dos modos de representação e ultrapassa, inclusive, as poéticas de vanguardas desenhadas a partir de estudos de escolas e propostas artísticas desenvolvidas na primeira metade do século XX em países europeus. O corpo nas artes contemporâneas pode se libertar de si mesmo e representar poéticas que foram providencialmente esquecidas e abafadas por apresentar signos que não seriam dignos de visibilidade.

A proposta de trazer à tona discursos que foram silenciados foi um dos lemes do pensamento decolonial desenvolvido por Walter Mignolo (2010) e também um dos valores de contemporaneidade proposto por Giorgio Agamben (2009). Pela sintonia entre os autores, é possível reconhecer que códigos, identidades, práticas e discursos foram negligenciados por não serem contemplados pelos discursos de poder.

A decolonidade também pode ser empreendida na elaboração de novas propostas de demonstrações do feminismo denominado como decolonial (LUGONES, 2019). De acordo com a autora, a necessidade de refletir sobre práticas e discursos feministas para além do universo eurocêntrico, branco e burguês torna-se uma necessidade epistemológica para avançar e contribuir para o campo de discussões. Assim, a partir dessas discussões, o texto pretende dialogar com a decolonialidade em movimentos artísticos e feministas que oferecem outras construções poéticas, tendo como referência as produções artísticas de Aleta Valente.

Na contramão de perspectivas cristalizadas sobre a representação do corpo e das artes, Aleta Valente, artista e performer, traça outro panorama ao reconfigurar signos e sentidos que não dialogam com processos estigmatizados sobre sexualidade e feminilidade. Ela propõe, em suas produções, a decolonização do corpo, do desejo e da condição de ser mulher ao evidenciar pelos pubianos, sangue menstrual e experiências vividas por mulheres em situação de vulnerabilidade.

Por acreditar na decolonização do corpo nas obras de Aleta, este texto pretende se debruçar sobre autores, autoras e conceitos que explicariam este fenômeno, não apenas enquanto construção científica, mas também como ação política de reconhecimento público. A importância de criar esse diálogo fortifica o campo interdisciplinar que envolve aspectos das artes e do feminismo como propostas prósperas para dilatar as representações dos corpos para além dos códigos previamente conhecidos.

Segundo Butler (2017a, p.185), a intenção de associar a arte às práticas do movimento feminista o liberta da rigidez terminológica e "(...) inspira um sentimento saudável de expansividade, resistência e subversão", ou seja, promove outras formas de atuação dentro do próprio movimento. Além disso, segundo as posições teóricas de Birolli e Miguel (2014), a arte pode ser considerada feminista 
e ativista, como as propostas de Aleta, por questionar as estruturas do patriarcado enquanto mecanismo de dominação e subordinação de mulheres, construindo outros discursos e representações sobre as diversas representações do gênero feminino. É importante salientar que as imagens do texto foram gentilmente cedidas pela artista para análise.

\section{Quadro Teórico}

Para começar a desenhar o arcabouço teórico deste artigo, é frutífero compreender algumas considerações. O primeiro deles é reconhecer a diferença entre o pensamento pós-colonial e decolonial. A ideia pós-colonial está amparada na condição de refletir como o pensamento eurocêntrico, branco e burguês ofereceu sustentação para que sujeitos e grupos de países europeus pudessem constituir realidades, fomentar culturas pela força da violência e, através desta condição, instaurar regimes de hierarquização e subjugação de grupos que não apresentavam as mesmas qualidades de poder. Assim foram concebidas as identidades das comunidades e países latino-americanos, africanos e asiáticos que foram, por sua vez, em grande maioria, ex-colônias europeias. Entretanto, a condição de subalternidade foi desenvolvida em contraste às práticas e aos discursos coloniais.

Edward Said (2007), um dos expoentes da epistemologia pós-colonial, apresenta em exemplos e pela própria vivência como a identidade e as representações sobre a cultura e povos orientais, na verdade, foram desenvolvidas a partir da concepção formada pela condição de sujeitos e grupos ocidentais. Ou seja, os códigos, símbolos e a cultura do universo oriental foram construídos como sendo exóticos ou estranhos simplesmente por serem diferentes da moral dos colonizadores europeus. A visão hierarquizada e superficial sobre o outro fundamenta ainda mais a ênfase à estratificação de representações sociais acerca das identidades e etnias alheias ao universo ocidental. Essa condição tem como sintoma a ocorrência de estratégias de violência contra tudo aquilo que é diferente do eu, além de marmorizar representações estereotipadas dos colonizados como sendo sujeitos e grupos selvagens, preguiçosos ou agressivos.

Como apontam Peter Burke (2004) e Stuart Hall (2016), a formação de estereótipos não contribui para a evolução de processos de significação, tampouco para o reconhecimento da condição do outro no espaço político ${ }^{1}$. Assim, o universo oriental, que não diz respeito apenas às referências geográficas, mas enquanto posicionamentos de dominação, foi erguido em referência ao universo ocidental, desenhando distinções sociais, morais e econômicas como civilidade $x$ barbárie, moderno $x$ atrasado, evoluído $x$ arcaico. Sob esse aspecto, os estudos pós-coloniais, que começaram a partir das lutas de independências das colônias europeias no período pós-guerra, buscaram construir outras referências epistemológicas levando em consideração a relação de interface edificada entre colonizador e colonizados.

Logicamente que os posicionamentos pós-coloniais tiveram (e ainda têm) muito a contribuir para o conhecimento científico, ainda mais dentro das ciências sociais e humanidades. Por outro lado, a necessidade de promoção cultural pelo

${ }^{1}$ Este artigo compreende o termo político sob o olhar apresentado por Hannah Arendt (2010, 1989). As contribuições de Arendt não foram articuladas enquanto movimento decolonial, nem é a proposta do artigo realizar essa aproximação. Entretanto, ela reconhece a política enquanto a organização do espaço público sob a condição de visibilidade, liberdade, pluralidade e comunicação de sujeitos livres e a intenção de quebrar qualquer uma dessas condições favorece o surgimento e prosperidade da violência. 
pensamento decolonial, não promove exatamente a interface das questões entre colonizados e colonizadores, mesmo reconhecendo que algumas práticas e discursos foram silenciados. A proposta decolonial caminha em outra direção e considera que a cultura e o conhecimento podem ser produzidos, promovidos e fomentados tendo como base de referências as próprias práticas que foram obscurecidas ou esquecidas por terem sido consideradas marginais, obsoletas ou inferiores.

Segundo Rosevics (2017), os estudos pós-coloniais se aproximam mais das correntes pós-modernas e de autores pós-estruturalistas como Michel Foucault (que compreendeu a sexualidade como dispositivo de poder) ou Jacques Derrida e Félix Guatarri que atribuíram críticas e reconsiderações à condição moral contemporânea. Sob essa ótica, a proposta pós-colonial, mesmo sugerindo reconfigurações epistemológicas, propõe-se a identificar e analisar as relações antagônicas entre as estruturas de poder entre grupos e sujeitos que são alvos do vigor do colonizador, denunciando as estratégias de dominação e opressão e promovendo a descentralização das narrativas. Sob outra ótica, ainda na esteira do pensamento de Rosevics, a crítica decolonial propõe como objeto de estudos não exatamente a presença e a interface com práticas e discursos coloniais ou de poder, mas, "o rompimento com a tradição eurocêntrica de decolonizar a epistemologia latinoamericana e seus cânones" (ROSEVICS, 2017, p. 180).

A proposta decolonial, além de estar envolvida com rompimento colonial, também está relacionada com a questão política. A intenção decolonial também se propõe a desvendar e reconfigurar conceitos acerca da modernidade. Condicionado à alegoria de desenvolvimento moral, tecnológico e científico, o movimento de modernidade que começou no século XVII e se estendeu ao longo dos oitocentos foi um sinal agudo de violência ao contemplar quase que exclusivamente a realidade branca e europeia para uso e fruição da condição moderna.

A situação de países pobres ou de sujeitos e grupos em condição de vulnerabilidade (negros, asiáticos, latino-americanos e africanos) não foi contemplada à promoção da modernidade; muito pelo contrário, esses grupos se tornaram motivo de exclusão e rechaço pela condição moderna. Os espaços de liberdade e visibilidade não se tornaram efetivos para o debate público na modernidade e, por isso, a necessidade de decolonização do pensamento. A qualidade de compreensão do pensamento decolonial torna-se frutífera no campo das ciências sociais e humanidades porque inclui novas perspectivas sobre as questões políticas e epistemológicas apresentadas, mas também sobre as manifestações artísticas. Walter Mignolo (2010) aponta que as artes podem oferecer com mais intensidade a condição de ser decolonial porque suas manifestações prezam pela:

(...) desobediência estética e institucional. A estética é abertamente política e decolonizada (...) as características imperiais de negação (...) é uma de suas tantas formas de desarmar essa montagem e construir subjetividades decoloniais². (MIGNOLO, 2010a, p. 15).

Em outro estudo, Mignolo (2010b) acredita na formação da gramática da

2 Original: "(...) desobediencia aesthetica y institucional. La estética es abiertamente política y decolonizadora (...) las caracteristicas imperiales de la negación (...) es una de suas tantas formas de desarmar ese montaje y construir subjetividades decoloniales" (MIGNOLO, 2010a, p. 15). 
decolonidade que reivindica a potência de teoria-outras como fundamentação do corpo dissidente. A ideia de teoria-outras atribui essa compreensão a partir de outras formas de pensar sobre a representação de sentidos e conhecimentos que operam fora dos estatutos dos discursos em vigência. A gramática da decolonidade oferece outra construção hermenêutica, agora plural, com o intuito de perceber que conflitos e cisões são fundamentais para suscitar discussões e formas de pensar decolonizando, inclusive, o corpo e a arte. Por esta perspectiva, encontram-se os corpos de sujeitos periféricos e subalternos, de gays, lésbicas, transexuais, travestis e outros estratos que não forjam a realidade dita desenvolvida ou reconhecida socialmente. Neste contexto também se encontra a obra e as representações do corpo de Aleta Valente em suas performances públicas e nas imagens distribuídas em seus perfis de redes sociais

\section{Decolonidade e contemporaneidade do corpo e da arte por Aleta Valente}

Aleta Valente é carioca, suburbana, além de ser a fantasia de si mesma. Nas redes sociais ela mantém o avatar ex-miss-febem, em alusão à figura da música Kátia Flávia, de Fausto Fawcett. Artista plástica e performer, ela passou por dois momentos pelos bancos acadêmicos, mas não concluiu o curso de Artes na Universidade Federal do Rio de Janeiro (UFRJ). Ela é moradora de Bangu, um bairro periférico reconhecido por ser um dos mais populosos da capital fluminense e por ser o endereço de um dos maiores complexos presidiários do país. Esse ambiente também é palco de muitas das suas expressões artísticas de onde divulga parte de seus trabalhos e dissemina humor, irreverência e desaforos.

Em diálogo com a decolonidade em tela desta pesquisa, as obras e performances de Aleta foram consideradas perversas e políticas, segundo o ponto de vista de Amaral e Arias Neto (2018). Para os autores, as obras da artista são perversas não porque apresentam algum ponto repugnante ou abjeto, mas porque desafia as estruturas de poder como sendo potência de criatividade e ressignificação de valores e sentido. Para além do entendimento da perversão pelo senso comum de ser alguma manifestação degradante, a perversão, neste caso, é tida como a prática que desestabiliza forças e promove enfrentamentos a códigos e práticas cristalizadas (ROUDINESCO, 2008), além de ser uma potência criativa (DUFOUR, 2013).

Em outro estudo sobre a atuação de Aleta, Ivana Bentes (2017) considera que as práticas artísticas e a visibilidade nas redes da artista são operações fora da condição de biopolítica pensada por Michel Foucault, que preza pelo controle e disciplina de corpos e subjetividades. Ainda na esteira do pensamento da autora, também amparada por Michel Foucault, as manifestações de Aleta podem ser consideradas sintoma da estética da existência, enquanto sujeitos que atuam como resistência à órbita dos discursos e códigos do mundo para melhor agir. A estética da existência produz sujeitos por outras linguagens e incentiva o movimento de liberdade e relações de existência em contraponto à ordem de padrões e normas convencionadas. Para a autora: 


\begin{abstract}
Esse sujeito autor reflexivo, que faz de si, do seu corpo, da sua vida a matéria de uma estetização contínua, se distancia cada vez mais das figuras do artista, do autor, marcadas pela lógica do espetáculo e da obra para se converterem em celebridades ou influenciadores. Figuras que nessa estetização em fluxo de suas vidas prescindem de uma obra e apresentam processos com potenciais disruptivos ou normativos. (BENTES, 2017, p. 94).
\end{abstract}

Para além das considerações apontadas pelos autores, que são frutíferas para a análise em andamento, as obras de Aleta podem ser decolonizadas porque ressignificam os valores das artes, de exposição e também de composição poética artística.

Nem sempre as obras dela poderão ser encontradas em espaços convencionais como museus, galerias e exposições, entretanto, um de seus trabalhos pôde ser visitado no Museu de Arte de São Paulo (Masp) na exposição "História da Sexualidade" ${ }^{3}$. Na oportunidade, ela expôs uma das suas selfies que integra a coleção "No Pregnant Series", também publicada no seu perfil nas redes sociais. Na imagem ela aparece trajando roupas brancas e na parte íntima há uma mancha vermelha como se fosse menstruação com a legenda "O patriarcado está vazando. A misoginia está vazando. Não seremos censurados". Tal obra foi motivo para que fosse açoitada verbalmente pelos internautas e muito criticada por dar visibilidade ao sangue menstrual. Suas obras podem ser consideradas decolonizadas justamente por oferecer outras perspectivas sobre o corpo da mulher e seus processos biológicos que, a despeito de serem naturais, são escondidos e abafados por uma perspectiva cultural normativa de controle dos corpos.

Além disso, a decolonidade da sua obra é percebida também pela sua subversão aos cânones das práticas artísticas, principalmente no que tange à poética estereotipada da feminilidade em fotografias e nas suas performances. De acordo com Goldenberg (1998), a proposta da performance é uma manifestação decolonizada ao reconhecer outras possibilidades de produção artística por ser uma iniciativa discursiva de ativismo social, protesto político e que forja a própria violação das fronteiras limitadoras de representação entre público e privado. Além disso, a autora apresenta que a performance preza pela fluidez das linguagens e intenções e esses valores estão muito presentes nas obras de Aleta.

Em outro estudo, Goldenberg (2001) considera que a manifestação performática, além de ser dissidente, desterritorializa os espaços de exibições e não há exclusividade na apresentação, assim, os espaços e os públicos podem ser flutuantes. Em outro apontamento, por ser moralmente provocativa, a performance abre margens para a possibilidade de ser assustadora e impactante, e essas qualidades, para Goldenberg (2001), descortinam as raízes dos tabus e dos medos que nos circulam. Ao realizar suas performances, Aleta decoloniza o corpo feminino, além de expressar com ironia e deboche enfretamentos aos machismos, sexismos e misoginias ao invadir o espaço público com sua proposta.

Aleta apresenta discursos e práticas feministas não convencionais, qualidades quistas para a moral decolonizada. Pelos pubianos e menstruação não são argumentos sígnicos comumente encontrados nas práticas artísticas. Esses elementos, como aponta Sibilia (2006) enquanto crítica, são qualidades "sempre 
ameaçadas de caírem no domínio das monstruosidades e das aberrações. Ou quiçá, pior ainda: da invisibilidade" (SIBILIA, 2006, p.277), por afrontarem os códigos da moral vigente e, assim, trazerem sinestesias que não deveriam ser compartilhadas. Sob esta perspectiva, a proposta de Aleta pode ser considerada decolonizada com amparo nas colocações de Pinto e Mignolo (2015). De acordo com os autores, a proposta decolonial se articula na intenção de oferecer e promover esforços para "desligamento ou desengajamento subjetivo, epistêmico, econômico e político em face da dominação" (PINTO; MIGNOLO, 2015, p. 384) que, no caso em questão, promove ironia e escárnio aos valores machistas e sexistas e ao sistema capitalista.

Sob outro ponto de vista, a moral decolonizada produz subjetividades resistentes que, como aponta Lugones (2019), se manifestam infrapoliticamente; ou seja, são ações que costumam abrir espaços em manifestações públicas e que não necessariamente são institucionalizadas por políticas governamentais, mas promovem a legitimidade, voz e visibilidade no espaço público. Por isso que a autora considera que a infrapolítica:

(...) marca um olhar para dentro, na política de resistência, rumo à libertação. Ela mostra o poder das comunidades oprimidas na construção de significados de resistência e de pessoas resistentes à constituição de significados e à organização social pelo poder. (LUGONES, 2019, p.362).

A proposta de decolonizar também as práticas do feminismo, faz parte das obras de Aleta quando suas obras reinventam outras propostas de manifestação. Em outro trabalho, ela debocha das belas-artes quando sugere a reconfiguração da origem do mundo. Em motejo à obra de Gustave Coubert, "L'origine du monde", pintada em 1866, o artista apresenta em tela uma vagina de modo muito realista e natural com os pelos pubianos em evidência. Em contrapartida, Aleta se fotografa em posição semelhante à tela do final do século XIX, entretanto com a vagina besuntada em sangue e intitula a obra de "L'origine du nouveau monde".

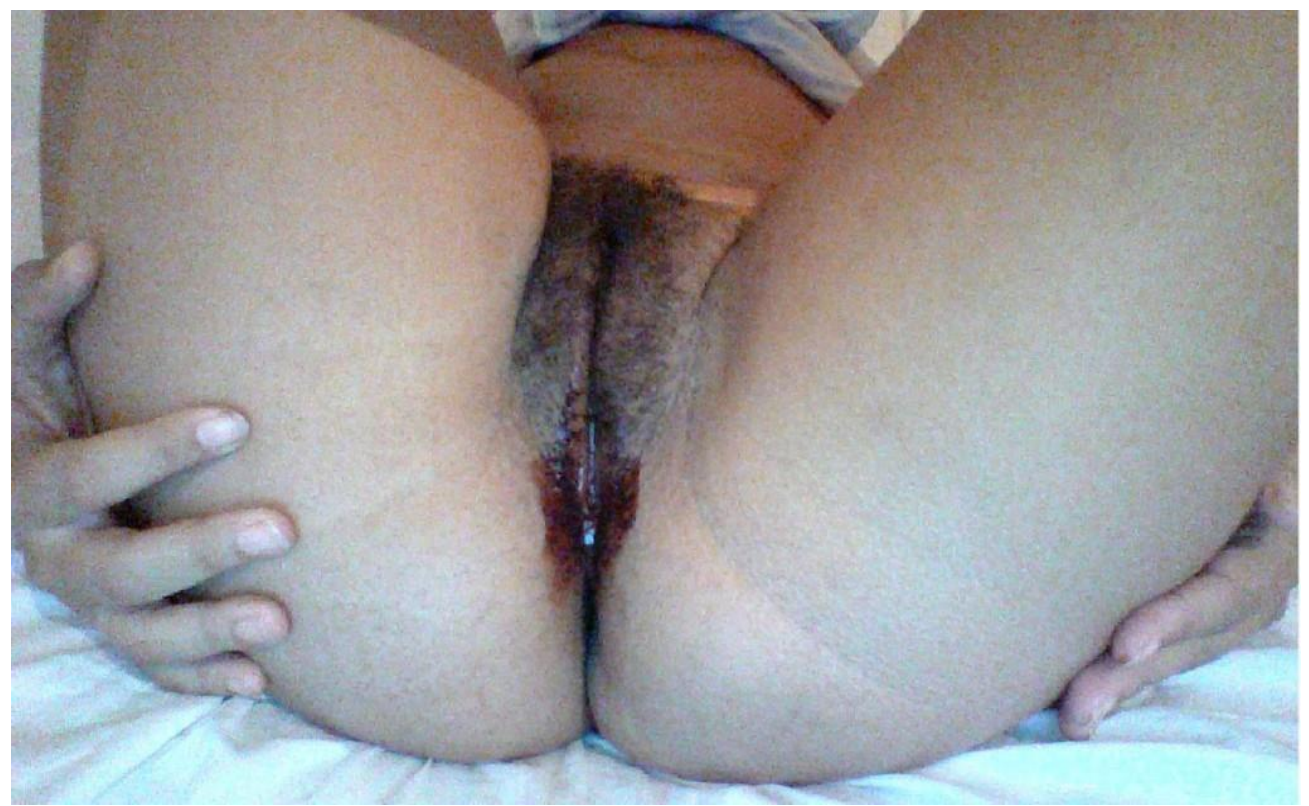

Figura 1 Obra L'origine de nouveau monde

Fonte: Reprodução gentilmente cedida pela artista 
Possivelmente, a intenção da autora não seja o desejo de aniquilar as práticas consagradas das artes, mas de fazer da sua proposta artística manifestação decolonizada no campo das artes e também de discursos contra as forças opressoras sobre a condição da mulher em sociedades patriarcais. Apresentar a vagina com sangue, ainda mais com esse título, sugere a possibilidade de pensar como é possível refazer outras iniciativas de potência de criação e criatividade, além de subverter códigos e signos que podem alcançar visibilidade.

Como apresenta Beauvoir (2016), o desejo, o prazer e gozo na sociedade patriarcal não foram reservados com ênfase às mulheres, mas foram direitos consagrados aos homens "ao passo que a mulher é confinada ao casamento: para ela o ato carnal; não sendo santificado pelo código, pelo sacramento, é falta, queda, derrota, fraqueza" (BEAVOUIR, 2016, p. 126).

Sob outro aspecto, além de decolonial, a obra de Aleta Valente pode ser considerada contemporânea a partir das considerações de Giorgio Agamben (2009). Como mencionado anteriormente, a modernidade ficou restrita à burguesia europeia, excluindo sujeitos e grupos de outros continentes ou que não pertenciam às classes privilegiadas. Esta crítica à modernidade também faz parte do pensamento de Agamben quanto à formação do conhecimento na contemporaneidade.

Para o filósofo italiano, a contemporaneidade apresenta uma relação particularizada sobre o tempo que não consiste exatamente com o comprometimento na produção e reprodução de práticas convencionalmente estabelecidas. Para ele, aqueles que aderem aos discursos vigentes não poderão ser considerados contemporâneos porque não conseguem promover o desprendimento e desapego que a condição requer de reconfiguração conceitual. Para além disso, Agamben também reconhece que a qualidade de ser contemporâneo é manter-se atento aos olhares do seu tempo e não perceber apenas aquilo que é alvejado pela luz, mas também perceber que as sombras e as práticas que são obscurecidas também fazem parte da contemporaneidade. De acordo com o autor, é "contemporâneo apenas quem não se deixa cegar pelas luzes do século e consegue entrever nessas a parte da sombra, a sua íntima obscuridade (...) é aquele que recebe em pleno rosto o facho de trevas que provém do seu tempo." (AGAMBEN, 2009, p. 63-64).

Este modo de compreender a contemporaneidade reconhece fraturas sobre o presente. Segundo o autor, ao mesmo tempo em que há a intenção de contemplar a escuridão, há a proposta de perceber na imensa escuridão a possibilidade de existência de luz que, "dirigida para nós, distancia-se infinitamente de nós" (AGAMBEN, 2009, p. 65). Ou seja, ao mesmo tempo que a escuridão está presente entre nós, não é exatamente parte de nós, por isso a descontinuidade lacunar para compreender o tempo presente conforme a contemporaneidade sugerida pelo autor. Todavia, o tempo cronológico não é suficiente para significar a contemporaneidade, esta qualidade do tempo carrega em si "algo que urge dentro deste e que o transforma. (...) $\mathrm{E}$, do mesmo modo, reconhece nas trevas do presente a luz que, sem nunca poder nos alcançar." (AGAMBEN, 2009, p. 65-66). 


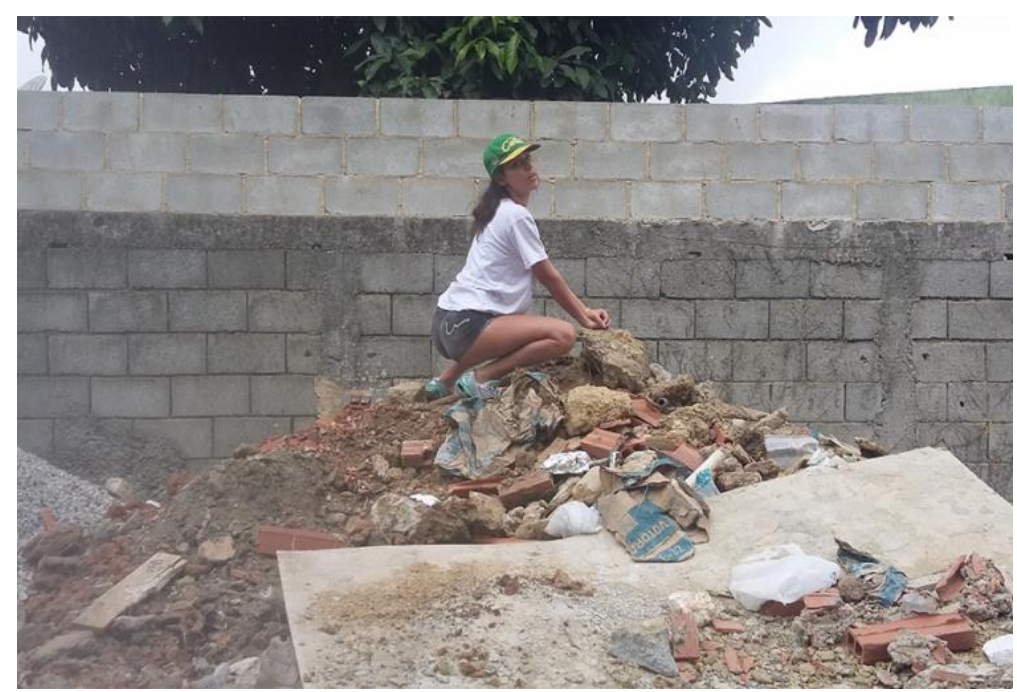

Figura 2 Obra Material girl

Fonte: Reprodução gentilmente cedida pela artista

O entendimento sobre as faces da contemporaneidade pode ser reconhecido nas obras e performances de Aleta quando ela traz aquilo que se encontra na obscuridade do sujeito e no limbo da visibilidade política. Mesmo em tom de deboche, a aridez da periferia suburbana também faz parte das suas ambientações artísticas. Em "Material girl", ela aparece sobre entulhos da construção civil acenando aos interlocutores. O título da sua atuação carrega o mesmo nome da música interpretada por Madonna, desde 1984, quando a cantora faz críticas ao comportamento individualistas e frívolos da sociedade de consumo. Já em "Brics Woman", aparentemente na mesma oportunidade em que produziu "Material girl", Aleta fica de quatro em frente a uma parede de tijolos empilhadas. Em outra produção, apenas uma boca entreaberta marcada por herpes oferece o enredo de "Sexy with herpes". Elementos e situações que possivelmente não seriam retratados em situações convencionais das artes são argumentos empreendidos na produção de Aleta. A sutileza e a leveza não integram as formações poéticas das suas obras. Aleta é contemporânea por trazer à tona a grossura e a esterilidade de cenas que, possivelmente, integram o cotidiano de regiões que se encontram sob a obscuridade.

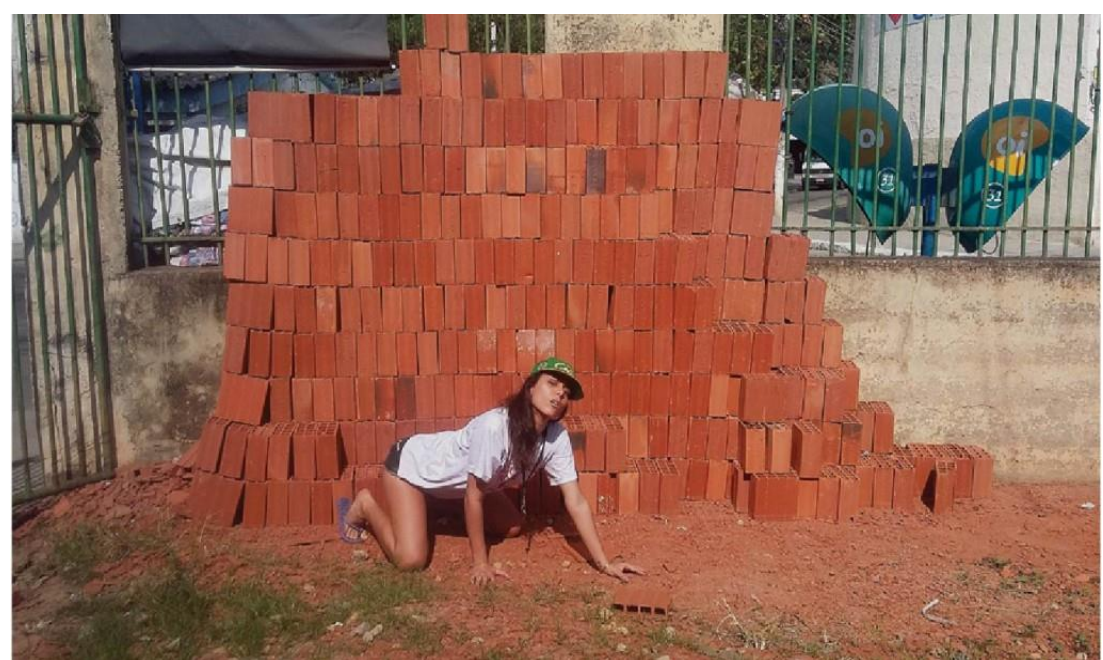

Figura 3 Obra Obra Brics Woman

Fonte: Reprodução gentilmente cedida pela artista 
Acompanhando o pensamento de Lugones (2019), a performance de Aleta flerta com a resistência decolonial porque evidencia as fraturas provocadas, isto é, é sintoma da qualidade de quebra da ordem colonial e provoca a promoção de formas "criativas de pensar, comportar-se e se relacionar, que são antiéticas à lógica do capital" (LUGONES, 2019, p. 372). Suas obras são sintomas do presente, mas que é esquecido e, na mesma proporção, se tornam potências de críticas e resistências para a decolonidade do corpo, da sexualidade e da política.

Na performance "Sabrina", de 2016, Aleta encena uma passagem verídica sobre a realidade de mulheres encarceradas. A artista reconstruiu a cena em que uma interna deu à luz a uma criança dentro da penitenciária, mas foi privada de auxílio médico-hospitalar. O acontecimento teve cobertura da imprensa e a legenda escolhida por Aleta para registrar a performance foi um trecho de uma matéria veiculada naquela época: "a presa saiu do isolamento com o bebê no colo e o cordão umbilical ainda no útero". Pela manifestação, Aleta elabora o discurso de descaso frente à realidade carcerária enfrentada por mulheres gestante e a condição subumana em que essas mulheres se encontram.

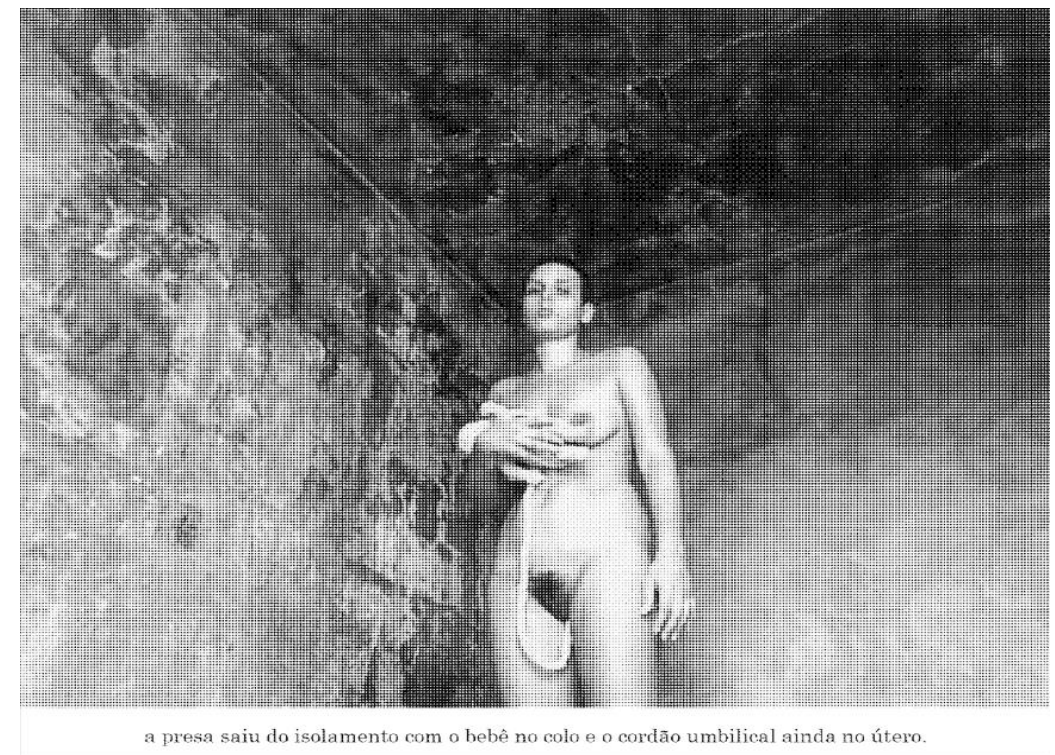

Figura 4 Obra Sabrina (2016)

Fonte: Reprodução gentilmente cedida pela artista

Ao estabelecer relação entre arte e feminismo, Aleta vai ao encontro do entendimento de Butler (2017) de que algumas vidas são precárias porque são consideradas indignas de pertencerem ao espaço público, entretanto há a resistência e a indignação dos corpos:

(...) quando os corpos se reúnem com a finalidade de expressar sua indignação e representar sua existência plural no espaço público, estão pleiteando demandas mais amplas: estes corpos solicitam que os reconheça e os valorize, a contento que exerçam seu direito de aparição, sua liberdade e clamem por uma vida vivível ${ }^{4}$. (BUTLER, 2017b, p. 33).

${ }^{4}$ Original: "(...) cuando los cuerpos se reúnem con el fin de expresar su indignación y representar su experiencia plural en el espacio publico, están planteando a la vez demandas más amplas: estos cuerpos solicitan que se los reconozca, que se los valore, al tiempo que ejercen su derecho a la aparición, su libertad y reclaman una vida vivible". (BUTLER, 2017b, p. 33) 
O entendimento de Butler se associa à perspectiva Arendt sobre política que, por sua vez, dialoga com a proposta decolonial de oferta de visibilidade e com a ideia de Agamben sobre modernidade ao trazer à tona a diversidade e pluralidade de representações que são deliberadamente excluídas. Em grande medida, a obra de Aleta se articula com o propósito de fugir das representações estereotipadas do desejo e das estratégias de representação da mulher e do feminino ao promover a decolonidade do corpo. Além disso, Aleta pode ser considerada contemporânea por fraturar as vértebras do seu tempo, fazendo uso do pensamento de Agamben, ao voltar holofotes à marginalidade que é invisível na mesma proporção que é altamente hodierna ao nosso tempo e não tem como negá-la.

\section{Considerações finais}

A proposta de decolonizar o corpo e as manifestações artísticas não deixa de ser ação política a partir do momento que preza pelo reconhecimento e visibilidade de sujeitos e grupos marginalizados. Esta consideração fortalece a hipótese do texto de considerar que as obras e performances de Aleta Valente podem ser consideradas decolonizadas, uma vez que ela traz à tona discursos e representações silenciadas por estratégias de poder.

Sob outro ponto de vista, seus trabalhos também podem ser considerados contemporâneos porque conseguem atrair a atenção e promover representações de sentidos que se escondem na escuridão do tempo presente. Produzir essas ações é promover outros sentidos das artes e das representações do corpo. Decolonizar é também abrir espaços para o reconhecimento de outros universos e de outras propostas discursivas para a ação política e também para as práticas das artes e do feminismo.

Aleta não está sozinha nessa empreitada decolonial. A necessidade de reconfigurar as artes, representações sobre corpo, sexualidade, gênero e ações feministas também podem ser vistas nas performances e trabalhos da artista e professora Fernanda Magalhães. Ela apresenta uma série de produções que trazem à luz elementos silenciados enquanto padrão de saúde e representações do corpo feminino. Em 2016, ela encenou o manifesto "Grassa crua", em crítica às tecnologias de controle e disciplina do corpo. Gorda, em cima de um banco minúsculo, a artista se despe até à nudez total e evidencia a angústia de acompanhar os discursos colonizantes sobre o corpo. A temática do corpo é recorrente às obras de Fernanda como, por exemplo, em 1995 quando lançou a série "A representação da mulher gorda nua na fotografia", em que apresentou mulheres gordas, inclusive a si mesma, em técnicas híbridas de fotografia, colagem e pintura. Essas mulheres tornam-se decolonizadas quando, a partir do seu universo e condição contextual, conseguem reconfigurar subjetividades e representações. 


\section{Referências}

AGAMBEN, Giorgio. O que é o contemporâneo e outros ensaios. Chapecó: Argos, 2009.

AMARAL, Muriel Emídio Pessoa do; ARIAS NETO, José Miguel. A montagem perversa positiva na revista Nin. Famecos: Mídia, cultura e tecnologia, Porto Alegre, v.25, n. 1, p.1-27, 2018. DOI: http://dx.doi.org/10.15448/1980-3729.2018.26869.

ARENDT, Hannah. A condição humana. Rio de Janeiro: Forense-Universitária, 1989.

ARENDT, Hannah. A promessa da política. 3aed. Rio de Janeiro: Difel, 2010.

BEAUVOIR, Simone de. O segundo sexo: a experiência vivida, v. 2, - 3.ed. Rio de Janeiro: Nova Fronteira, 2016.

BENTES, Ivana. Biopolítica feminista e estéticas subversivas. Matrizes: São Paulo, v.11, n. 2, p. 93-109, 2017. DOI: http://dx.doi.org/10.11606/issn.1982-8160.v11i2p93-109.

BIROLI, Flávia; MIGUEL, Luis Felipe. Feminismo e Política: uma introdução. Rio de Janeiro: Boitempo, 2014.

BURKE, Peter. Testemunha ocular: história e imagem. Bauru, SP: EDUSC, 2004.

BUTLER, Cornelia. Arte e feminismo: uma ideologia de critérios em transformação. In: PEDROSA, Adriano; MESQUITA, André. História da sexualidade: antologia. São Paulo: MASP, 2017a.

BUTLER, Judith. Cuerpos aliados y lucha política. Cuidade Autónoma de Buenos Aires: Paidós, 2017b.

DUFOUR, Dany-Robert. A cidade perversa: liberalismo e pornografia. Rio de Janeiro: Civilização Brasileira. 2013.

GOLDEnBerg, Roselee. Performance: live art since the 60's. London: Thames and Hudson, 1998.

GOLDENBerg, Roselee. Performance art: from futurism to the present. London: Thames \& Hudson, 2001.

HALL, Stuart. Cultura e representação. Rio de Janeiro: Puc-Rio; Apicuri, 2016.

LUGONES, Maria. Rumo a um feminismo decolonial. HOLLANDA, Heloisa Buarque (org.) Pensamento feminista: conceitos fundamentais. Rio de Janeiro: Bazar do tempo, 2019.

MIGNOLO, Walter D. Aiesthesis Decolonial. Calle 14. La Rioja, v. 4, n. 4, p. 10-25, 2010a.

MIGNOLO, Walter. Desobediencia epistémica: retórica de la modernidad, lógica de la colonialidad y gramática de la descolonialidad. Buenos Aires: Ediciones del Signo, 2010b. 
PINTO, Júlio Roberto de Souza; MIGNOLO, Walter D. Civitas. Porto Alegre, v. 15, n. 3, pp. 381-402, 2015.

ROSEVICS, Larissa. Do pós-colonial à decolonialidade. In: CARVALHO, Glauber. ROSEVICS, Larissa (orgs.). Diálogos internacionais: reflexões críticas do mundo contemporâneo. Rio de Janeiro: Perse, 2017, p. 173-178.

ROUDINESCO, Elisabeth. A parte obscura de nós mesmos: uma história dos perversos. Rio de Janeiro: Zahar, 2008.

SAID, Edward. Orientalismo: o oriente como invenção do ocidente. Rio de Janeiro: Companhia do Bolso, 2007.

SIBILIA, Paula. O bisturi de software: como fazer um "corpo belo" virtualizando a carne impura? In: ARAUJO, Denise Correa (org.). Imagem (Ir) realidade: comunicação e hipermídia. Porto Alegre: Sulina, 2006, p. 271-289. 